\title{
AN ELECTROSTATIC LOWER STATOR AXIAL GAP WOBBLE MOTOR: DESIGN AND FABRICATION
}

\author{
Rob Legtenberg, Erwin Berenschot, John van Baar, Theo Lammerink and Miko Elwenspoek \\ MESA Research Institute, University of Twente, P.O. Box 217, 7500 AE Enschede, The Netherlands
}

\section{SUMMARY}

The fabrication, initial modelling and first results of an electrostatic lower stator axial gap wobble motor are presented. The four mask fabrication process is based on polysilicon surface micromachining techniques. Three to twelve stator pole wobble motor designs have been realized with rotor radii of 50 and 100 micrometer. A theoretical model predicts torque generations in the $\mathrm{nNm}$ range at high electrostatic fields. Motors have typically been operated between 10 and 20 Volts. Initial experimental results are presented.

\section{INTRODUCTION}

Because of large estimated driving torques, initial micro mechanical motor design and fabrication attempts have been axial-gap architectures $[1,2]$. However these designs suffered from instabilities in tilting and to a lesser extent in vertical pertubations and fabrication complexity, that finally led to the development of radial-gap or side-drive micromotors [3-5]. In most cases a radial-gap design consists of a pinned rotor structure that is surrounded by a number of stator poles. By proper commutation of the charge distribution, on the stator electrodes and the rotor, continuous motion of the rotor can be achieved. Two designs were succesfully realized: salient pole- and wobble motors. Although the performance of these micromotors is still emerging, they suffer from two principle drawbacks. Firstly, the rotor-stator overlap is small which results in small driving torques; typically a few $\mathrm{pNm}$ for salient pole micromotors and a few tens of $\mathrm{pNm}$ for wobble motors. This is merely the result of the rotor and stator thickness that is generally only a few microns. Secondly, it is difficult to implement the radial gap design in a mechanical system for transduction purposes. In outer stator designs the stator completely surrounds the rotor making it difficult to transfer the mechanical energy to a mechanical structure by planar fabrication techniques. While for inner stator designs it is difficult to make the electrical stator connections $[6,7]$.

A number of different side-drive wobble motors have been investigated [5-9]. Wobble motors are able to generate larger driving torques compared to salient pole micromotors because of their gear ratio. The gear ratio increases the driving torque at the cost of a decreasing angular speed. A further advantage of wobble motors is that friction is expected to be lower because of a rolling motion instead of sliding at the bearing.
A lower stator axial gap wobble motor design can probably solve some of the limitations of the radial-gap or side-drive design. This design was first presented by Paratte $[10,11]$. The tilting-, vertical- and radial rotor instabilities of this lower stator axial gap design are constrained by the bearing and stator geometry. The larger rotor to stator overlap results in a larger torque generation and succesfull drive of a gear train has already been realized by a hybrid design based on electroplating and assembling techniques [12]. In this paper a new fabrication process is presented as well as estimated torque generation for this type of micromotors. The motor design and fabrication process lends itself for future on-chip micromotor driven micro mechanical systems.

\section{OPERATION PRINCIPLE}

The motor is sketched in fig. 1. The rotor is resting, at the center, at a pin- or ball bearing. When a potential difference between the rotor and one of the stator poles is applied, the rotor will be pulled down towards a contact point at the angular center of the excited stator pole. This results in an inclined position of the rotor.

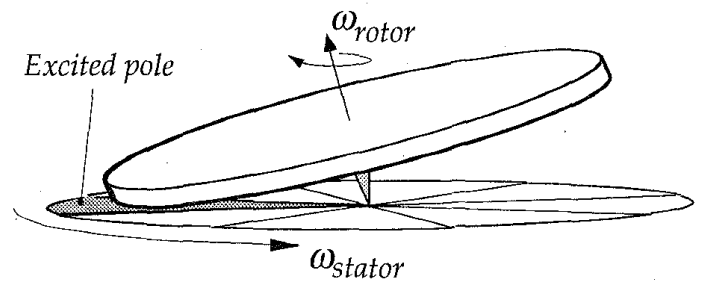

Fig. 1 Sketch of the operation principle.

Switching to other stator poles will move this contact point around and the rotor is forced to roll at it's outer radius resulting in a rocking motion. Because of a difference in radius between the rotor and the resulting contact point circle, the rotor will be rotated by a small angle after one sequential activation of all stator poles.

\section{GEAR RATIO}

For small rocking angles $(\mathrm{d}<<\mathrm{R})$ the harmonic reduction ratio of the angular velocity between the stator and rotor is given by the nominal gear ratio $n_{O}$ (fig. 2):

$n_{0}=\frac{2 R^{2}}{d^{2}-2 d h_{b}}$ 


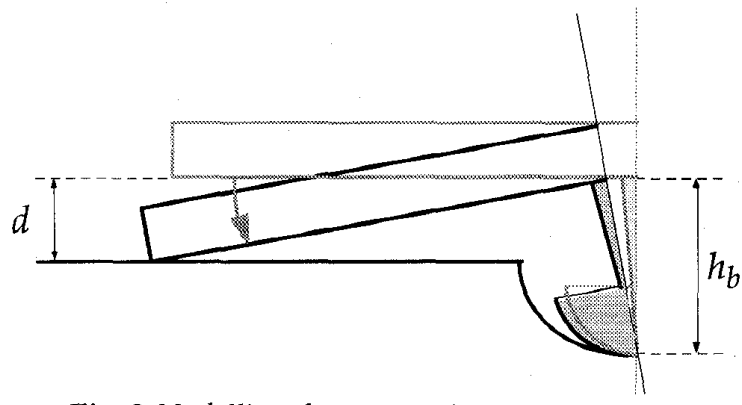

Fig. 2 Modelling the gear ratio.

where $R$ is the rotor radius, $d$ is the axial gap distance at the rotor center and $h_{b}$ is the heigth of the bearing pin. Note that the gear ratio is negative because the rotor rotates in a direction opposite to the excitation direction of the stator poles. When the bearing pin heigth is equal to $d$, equation (1) reduces to $-2(R / d)^{2}$.

\section{TORQUE GENERATION}

The tilt angle of the rotor is very small. Therefore the electrostatic field can be assumed to be vertical. Furthermore, fringing fields have been neglected and the rotor is assumed to be rigid.

The torque generated by the motor can be found from the derivative of the potential energy with respect to the rotor angle $\alpha$. This results in the following expression for the torque:

$$
\tau=-\frac{1}{2} \int_{\varphi_{1}}^{\varphi_{2}} \int_{R_{i}}^{R_{o}} \frac{\varepsilon_{0} r^{2} \sin (\varphi-\alpha) V^{2}}{\left.\frac{R}{d}\left(d 1-\frac{r}{R} \cos (\varphi-\alpha)\right]+\frac{d_{i n s}}{\varepsilon_{r}}\right)^{2}} d r d \varphi
$$

where $\alpha$ is the angle of the rotor contact point, $\varphi$ is the angle of the stator pole from $\varphi_{1}$ to $\varphi_{2}, r$ is the radius of the stator pole from $R i$ to $R o, d_{i n s}$ is the thickness of the insulating layer with a relative dielectric constant $\varepsilon r$ between the rotor and the stator and $V$ is the applied voltage between the stator and the rotor.

An example of the single phase torque as function of the rotor angle $\alpha$ is shown in fig. 3 for a three stator pole design. The rotor radius is $100 \mu \mathrm{m}$, the gap distance is 2 $\mu \mathrm{m}$, and the dielectric layer between the stator and rotor has a thickness of $0.2 \mu \mathrm{m}$ and a relative dielectric constant of 7.5. The outer radius of the stator pole is equal to the rotor radius and the inner radius is equal to half the rotor radius $(50 \mu \mathrm{m})$. The driving voltage is equal to 100 Volts. The maximum torque generation for this type of motors, at given dimensions, can be in the range of $\mathrm{nNm}$ at high electrostatic fields

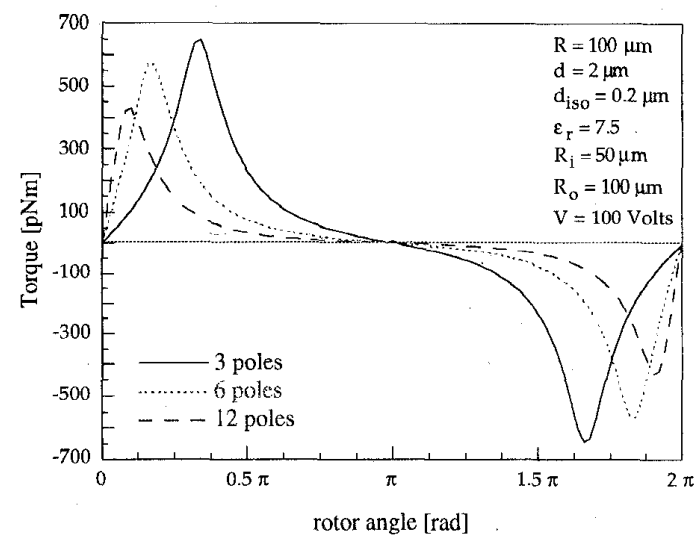

Fig. 3 Single phase torque as a function of the rotor angle for a 3,6 and 12 stator pole design.

\section{FABRICATION}

The fabrication process requires four masks and is described below. It starts with a (100) p-type 3" silicon wafer. First step is the deposition of a $1 \mathrm{~mm}$ thick stress reduced silicon nitride layer by LPCVD from $70 \mathrm{sccm}$ DCS and $18 \mathrm{sccm} \mathrm{NH} 3$ at $850{ }^{\circ} \mathrm{C}$ and a pressure of 200 mTorr. The next step is the deposition of a $0.5 \mathrm{~mm}$ thick polysilicon layer, grown by LPCVD at a temperature of $590{ }^{\circ} \mathrm{C}$, a pressure of $250 \mathrm{mT}$ Torr and a silane flow of 50 $\mathrm{sccm}$. This polysilicon layer is heavily doped with boron by solid source indiffusion for one hour at $1150{ }^{\circ} \mathrm{C}$. This yields a squared resistance of about $70 \Omega$. After boron indiffusion the BSG layer is stripped in a buffered HFsolution. After patterning, the doped poly layer forms the stator poles (fig. 4 a). Again a $0.5 \mu \mathrm{m}$ thick stress reduced LPCVD silicon nitride layer is deposited that serves as an insulator between the stator and rotor. Contact windows are opened in this $\mathrm{SiN}$ layer by RIE in a $\mathrm{CHF}_{3} / \mathrm{O}_{2}$ gas mixture in order to make contact with the stator poles later on (Fig. $4 \mathrm{~b}$ ). Now a $2 \mu \mathrm{m} \mathrm{SiO}_{2}$ layer is grown by PECVD from a $\mathrm{SiH}_{4} / \mathrm{N}_{2} \mathrm{O}$ gas mixture at $300{ }^{\circ} \mathrm{C}$, a pressure of $650 \mathrm{mTorr}$ and RF power of 60 Watt (fig. $4 \mathrm{c}$ ). The ball bearing is now formed by one lithography step and dry etching of the $\mathrm{SiO}_{2} / \mathrm{SiN}$ sandwhich layer and dry isotropic underetching of the silicon wafer. This is done by RIE the $\mathrm{SiO}_{2}$ layer using $\mathrm{CHF}_{3}$ at a pressure of $20 \mathrm{mT}$ Torr and a RF power of 50 Watt and the SiN layer by RIE using a $\mathrm{CHF}_{3} / \mathrm{O}_{2}$ gas mixture at a pressure, of $10 \mathrm{mT}$ Torr and a RF power of 75 Watt. The resist layer is removed by $\mathrm{O}_{2}$ plasma ashing and the silicon is underetched by dry isotropic etching in a $\mathrm{SF}_{6} / \mathrm{N}_{2}$ gas mixture at $100 \mathrm{~m}$ Torr and 50 Watt (fig. $4 \mathrm{~d}$ ). 
(a)

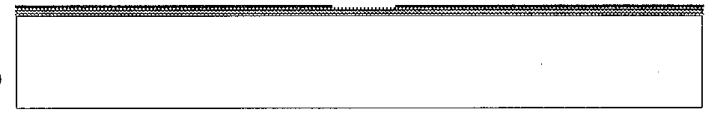

(b)

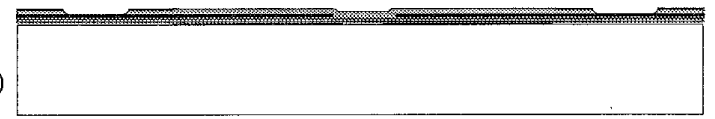

(c)

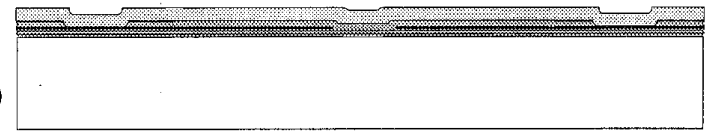

(d)

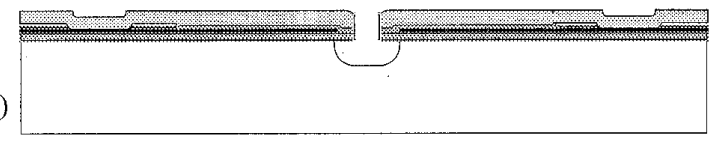

Fig. $4(a),(b),(c),(d),(e),(f),(g)$ Processing Sequence for the wobble motor. More details are given in the text.

Next a $1 \mu \mathrm{m}$ thick $\mathrm{SiO}_{2}$ layer is grown by LPCVD from TEOS at $700{ }^{\circ} \mathrm{C}$ and a pressure of $400 \mathrm{mTorr}$ (fig. 4 e). This layer defines the bearing spacing while the first $\mathrm{SiO}_{2}$ layer defines the gap spacing between the rotor and stator. Now the rotor is constructed. This starts with the deposition of a $2 \mu \mathrm{m}$ thick LPCVD polySi layer that is also doped by indiffusion as described above. The anneal step also reduces the residual stress of the polySi layer. After stripping the BSG layer in BHF a square resistivity of $6 \Omega$ is obtained. To increase the stiffness of the rotor a $6 \mu \mathrm{m}$ thick silicon layer is deposited by sputtering in Ar. This layer is annealed in a $\mathrm{N}_{2}$ atmosphere at $450{ }^{\circ} \mathrm{C}$ for 1 hour to reduce residual strain. A $0.6 \mu \mathrm{m}$ thick PECVD silicon oxide layer is grown that serves as an etch mask for the silicon sandwhich layer. After patterning the silicon oxide by $\mathrm{RIE}$ using $\mathrm{CHF}_{3}$ gas, the polysilicon is anisotropically etched using a $\mathrm{SF}_{6}, \mathrm{O}_{2}, \mathrm{CHF}_{3}$ gas mixture (fig. $4 \mathrm{f}$ ). The accumulated layers at the backside are stripped by dry etching, followed by a standard cleaning procedure. The sacrificial layers are etched in an HF (50\%) solution for $37.5 \mathrm{~min}$., and are DI rinsed and spin dryed. Last step is the evaporation of a $1 \mu \mathrm{m} \mathrm{Al}$ backside metallization layer (fig. $4 \mathrm{~g}$ ). The result is shown in fig. 5 and 6.

The motor operation requires a rigid rotor design with respect to vertical deflections in order to prevent rotor deformation and stiction problems between the rotor and stator surface. This can easily be accomplished by increasing the rotor thickness: Therefore the rotor structure is stiffened by deposition of a sputtered silicon layer that can easily be grown up to a thickness of several tens of $\mu \mathrm{m}$. To prevent problems with photoresist step coverage a ball bearing design has been used. The ball bearing is however not self-aligned like the flange bearing design [3] (e)

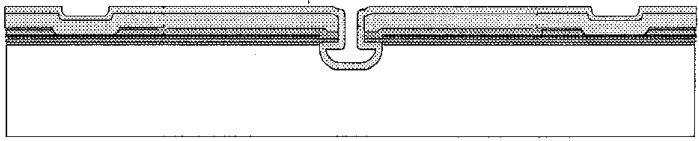

(f)

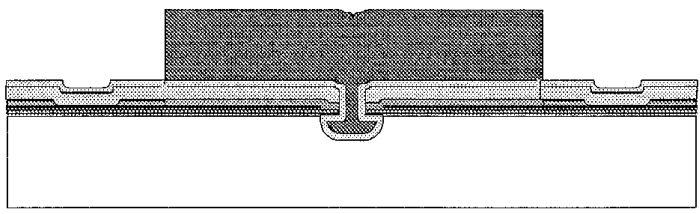

$(\mathrm{g})$

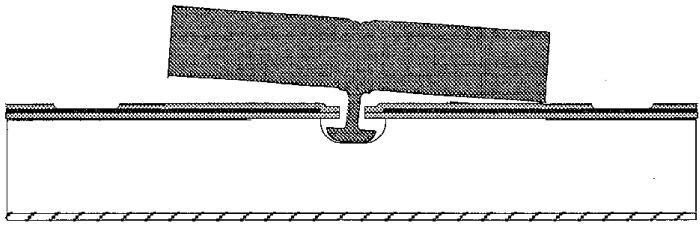

but alignment within $1 \mu \mathrm{m}$ should be possible and is not considered to affect the motor performance strongly. For thinner rotors or sufficiently good photoresist step overage also a flange bearing design for these type of motors can be realized. At this point no experimental or theoretical study on rotor thickness has been done. Note that the ball bearing design can also be realized with LIGA, or other molding and electroplating techniques.

\section{EXPERIMENTAL RESULTS}

Motors have been operated using a programmable power supply which controls the driving schemes. The driving frequency and the amplitude for a square wave signal of four independent output phases can, respectively, be varied between 15 and $100 \mathrm{kHz}$, and 0 to $100 \mathrm{~V}$. Single phase excitation schemes have been used, e.g. $\mathbf{A b c}, \mathrm{aBc}$, $\mathrm{abC}$ for a three stator pole design. Stator designs with a larger number of poles than the number of power supply phases are driven by symmetrically skipping the additional stator poles. Measurements have been performed in air under semi-cleanroom conditions after storage periods up to several weeks. The motors appeared to be very rigid and even operated after subsequent lithography and etching steps after the final release in $\mathrm{HF}$.

Starting voltages ranged from 7 to $15 \mathrm{~V}$, and stopping voltages ranged from 5 to $10 \mathrm{~V}$ for both rotor radii. Experimentally determined gear ratios varied between 130 and 200 for the $50 \mu \mathrm{m}$ rotor radius design, and between 600 and 1000 for the $100 \mu \mathrm{m}$ rotor radius designs.

The motor lifetime is limited from one hour to several minutes, depending on rotational speed that was varied from 0.5 to $500 \mathrm{rpm}$. Limited lifetime is suggested to result from wear at the ball bearing. 


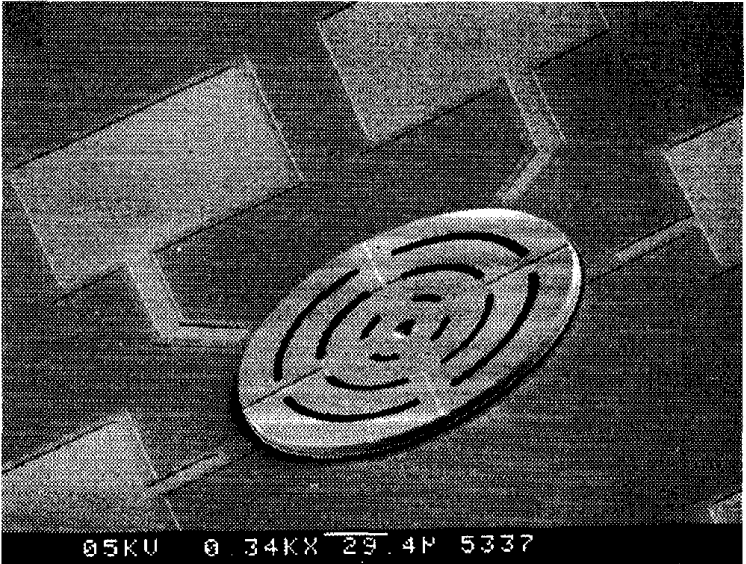

Fig. 5 SEM photorgraph of an electrostatic axial gap wobble motor with four stator poles. The rotor diameter is $200 \mu \mathrm{m}$ and rotor thickness is $8 \mu \mathrm{m}$.

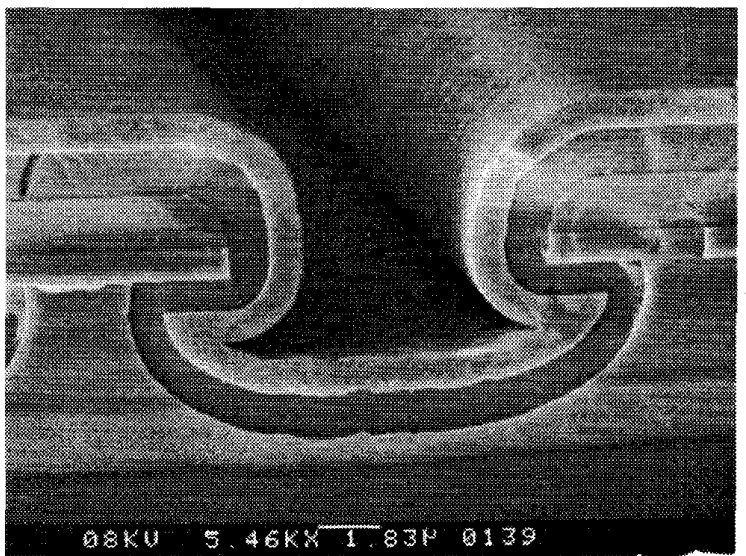

Fig. 6 SEM photograph the cross section of a ball bearing groove after deposition of the second polysilicon layer. The good step coverage of the TEOS and polysilicon layer is clearly visible.

\section{CONCLUSIONS}

An electrostatic lower stator axial gap wobble motor was succesfully fabricated by surface micromachining techniques. In contrast to side drive motors, the stator poles are located underneath the rotor instead of surrounding the rotor sides. This results in a higher torque generation and the ability to transfer the mechanical energy for driving purposes. The motor design and fabrication process lends itself for future on-chip micromotor driven micro mechanical systems. Measured starting voltages varied between 7 to $15 \mathrm{~V}$ and stopping voltages ranged from 5 to $10 \mathrm{~V}$. Experimental gear ratios around 165 and 800 are obtained for motors with rotor radii of respectively 50 and 100 micrometer. Motor lifetime is suggested to be limited by wear and ranged from a few minutes to one hour, depending on rotational speeds from 0.5 to $500 \mathrm{rpm}$.

\section{ACKNOWLEDGEMENTS}

The authors would like to thank Bert Otter for making the SEM photographs, Jeroen Sikkema for the fabrication of the power supply and Marina Maund for carefully reading the manuscript. This research is sponsored by the Dutch Technology Foundation (STW).

\section{REFERENCES}

[1] S. F. Bart, T. A. Lober, R. T. Howe, J. H. Lang and M. F. Schlecht, Design considerations for microfabricated electric actuators, Sensors and Actuators, 14 (3), 1988, pp. 269-292.

[2] T. A. Lober and R. T. Howe, Surface micromachining processes for electrostatic microactuator fabrication, Proc. IEEE Solid-State Sensor and Actuator Workshop, Hilton Head Island, SC, U.S.A. June 6-9, 1988, pp. 59-62

[3] IC-processed electrostatic micromotors, L.F. Fan, Y.C. Tai and R.S. Muller, Sensors \& Actuators, Vol. 20, 1989, pp. 41-47.

[4] L.S. Tavrow, S.F. Bart and J.H. Lang, Operational characteristics of microfabricated electric micromotors, Sensors \& Actuators A, Vol. 35, 1992, pp.33-44.

[5] M. Mehregany, S.D. Senturia, J.H. Lang and P. Nagarkar, Micromotor fabrication, IEEE Transactions on electron devices, Vol. 39, No. 9, Sept. 1992, pp. 2060-2069.

[6] T. Furuhata, T. Hirano, L. H. Lane, R. E. Fontana, L. S. Fan and H. Fujita, Outer rotor surfacemicromachined wobble motor, Proc. IEEE Micro Electro Mechanical Systems, Fort Lauderdale, Fl, U. S. A., February 7-10, 1993, pp. 161-166.

[7] K. Deng and M. Mehregany, Outer-rotor polysilicon wobble motors, Proc. IEEE MEMS, Oiso, Japan, January 25-28, 1994, pp. 269-272.

[8] W. Trimmer and R. Jebens, Harmonic electrostatic motors, Sensors and actuators, 20 (1989), pp. 17-24.

[9] S.C. Jacobsen, R.H. Price, J.E. Wood, T.H. Rytting and $M$. Rafaelof, A design overview of an eccentricmotion electrostatic microactuator, Sensors and actuators, 20 (1989), pp. 1-16.

[10] L Paratte and N.F. de Rooij, A rigid ring electrostatic harmonic wobble motor with axial field, Proc. International Conference on Solid-State Sensors and Actuators, Transducers '91, San Francisco, CA, U.S.A., June 24-27, 1991, pp. 890-893.

[11] L Paratte and N.F. de Rooij, A rigid ring electrostatic harmonic wobble motor with axial field, Proc. International Conference on Solid-State Sensors and Actuators, Abstracts of late news papers, Transducers '93, Yokohama, Japan, June 7-10, 1993', pp. 4-5.

[12] L. Paratte, H. Lorenz, R. Luthier and N.F. de Rooy, Miniature gear reduction unit driven by a silicon electrostatic wobble motor, I.Micromech. Microeng.. 2 (1992), pp. 221-223. 